\title{
EL DERECHO CONSTITUCIONAL COMO DERECHO
}

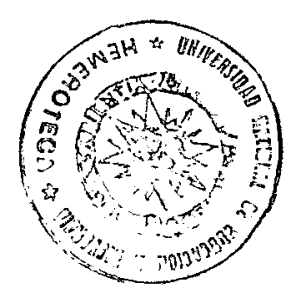

Madrid, 15 de junio de 1982.

Sr. D. Oscar Alzaga

Director de la

«Revista de Derecho Político»

UNED

MADRID

Querido director y amigo:

He visto con asombro el largo artículo que me dedica en el número 13 de esa Revista el profesor Pablo Lucas Verdú bajo el título «El Derecho Constitucional como Derecho Administrativo (La 'ideología constitucional' del profesor García de Enterría)». Nadie nunca se había ocupado con tanta atención de mi modesta obra, y ése es el primer y sincero motivo del asombro.

El segundo es el contenido mismo de dicho artículo, asombro éste que se diversifica ya en varios submotivos, que voy a intentar explicar sin el menor afán polémico.

Porque pocas cosas deseo menos, en efecto, que enzarzarme ahora en un «cuerpo a cuerpo» dialéctico con mi colega y amigo. Las cuarenta y ocho nutridas páginas que me dedica podrían convertirse en mi respuesta en otras tantas, y aun fácilmente más si llegase a abrirse turno de réplica y de dúplica; lo cual es un panorama verdaderamente tenebroso para cualquier lector, por animoso que sea y por amigo (o quizá enemigo) de los dos o de alguno que se figure ser. Es obvio que «el fuego no vale la cerilla que ha de encenderlo», como suelen decir los franceses, porque el tema en sí, mi concepción del Derecho Constitucional, mi personalidad, real o supuesta, y hasta la escasamente penetrante -a mi juicio, aunque comprendo que sea recusable- «reducción» marxista que intenta de mi obra, es una materia absolutamente banal y sin el menor interés objetivo. 
Opto, por ello, por explicarte a ti, director de la Revista, y a través de ti a tus lectores, si lo creyeses oportuno, las razones de ese asombro mío, que imagino que alguien más que yo compartirá, dejando entero el campo a mi amable crítico en cuanto al tratamiento sustantivo de los temas.

Quizá me interese sólo hacer una puntualización a uno de los puntos de hecho de que mi censor parte: que yo he hecho en el prólogo a mi libro La Constitución como norma y el Tribunal Constitucional una desvalorización en bloque del escalafón entero de profesores de Derecho Político. Dios me libre de una intención tan temeraria e irresponsable. Siento por la mayor parte de los que conozco y trato el mayor afecto y también el mayor respeto científico, como además proclamo allí. Mi agresividad es, por otra parte, muy corta, por mi talante y hasta por mi edad, ya nutrida, y la materia inadecuada, porque es difícil que alguien pueda creer en «razas» administrativas, esto es, en capacidades distribuidas milagrosamente según el orden de los escalafones; sólo los espíritus más que rurales pueden llegar a creer que la gente de su pueblo reúne todas las excelencias y que esa sorprendente ventura se corresponde paralelamente de modo milagroso con las desventuras concentradas en el pueblo vecino. Si alguna capacidad me reconoce mi amable crítico, y debo decir que es más bien generoso en proclamarlas, concédame al menos ésa de un discernimiento tan elemental.

Tampoco podrá leerse en dicho prólogo, me parece, algo tan absurdo como que por pertenecer a dicho escalafón se sea ya incapaz de hacer ciencia jurídica. Lo único que he querido decir, por lo que veo ahora con escasa fortuna, es que la dirección absolutamente predominante de los profesores de Derecho Político, la de la ciencia política, o la historia o la filosofía (en la antropología, diré incidentalmente para responder a la sorpresa que declara Lucas Verdú, han concluido profesores como Javier Conde o Nicolás Ramiro, por no citar más que a los muertos, los dos, por cierto, de indiscutible calidad), que esa dirección no llegará a encontrar nunca al Derecho Constitucional, que es otra dirección enteramente distinta y perfectamente separada. Punto. Que por ello, es menester, por una parte, separar, como se ha hecho en todo el mundo occidental, con la única excepción de Francia, excepción en este momento sumamente criticada en Francia misma, las dos disciplinas, la Ciencia política del Derecho Constitucional, lo cual no creo que sea hacer de menos a ninguna de ellas, sino más bien lo contrario, sustantivarlas y robustecerlas; $\mathrm{y}$, segundo, admitir lo que en todo el mundo también ( $\mathrm{y}$ aquí ya sin excepciones; últimamente vea en Bélgica, país incluido en la órbita científicojurídico francesa, lo que dice sobre el tema F. Delpérée, Droit Constitutionnel, tomo I, Bruxelles, 1980, págs. 46 y sigs.; y respecto a la relación Derecho Constitucional Ciencia Política, págs. 50 y sigs.; en este último caso hay «emprunts», préstamos recíprocos; en el primero, Derecho ConstitucionalDerecho Administrativo, «une unité foncière», una unidad radical; ¡bien es verdad que este autor viene del Derecho Administrativo!) es igualmente patente, la unidad del Derecho Público del Estado, que engloba al Derecho Constitucional y al Derecho Administrativo, como por lo demás ocurrió en España hasta bien entrado este siglo. Sería lamentable confundir «asignaturas» de un plan de estudios con «ciencias» sustantivas. 
Esa apelación a la unidad es todo lo contrario, me parece, que un segregacionismo como el que se me imputa y que, más bien, es el que luce paladinamente en el artículo que comento. Lucas Verdú parece creer en la distinción zoológica de las especies de administrativistas y politicistas. Yo no. Esa es una diferencia bastante precisa.

Por ello, me parece ocioso decir que muchos, aunque minoritarios, profesores de Derecho Político se han orientado hacia estudios jurídicos, antes y ahora, aunque más ahora, por razones perfectamente comprensibles (sin necesidad de hacer «reduccionismo» ideológico como el que practica a mi costa Lucas, y reduccionismo tan basto como insinuar que acaso pueda haber en ello intereses profesionales - como podrá verse que de mí pretende-). El que el artículo haga la nómina de estos constitucionalistas me parece, obviamente, ocioso, pues yo no he discutido absolutamente nada en ese terreno y, antes bien, me complace proclamar mi deuda personal para con muchos de ellos, y aun con el mismo Lucas Verdú, en las escasas veces en que ha prestado su atención a estas cuestiones como verdaderas cuestiones jurídicas.

Lo que más me sorprende del artículo que comento es su propia sorpresa ante mi posición, que es el simple recuerdo de lo que es absolutamente común en el ancho mundo. Olvídese un momento el profesor Lucas de Duverger, al que luego volveremos, y contemple lo que se escribe en todas las lenguas bajo el rótulo de Derecho Constitucional. Compruebe que esa materia es una, y otra distinta la ciencia política, y que es más que extraño que una y otra tengan hoy los mismos cultivadores, diversificación explicable por la diferencia radical de los respectivos métodos.

Especialmente interesante me parece el caso anglosajón, por dos razones: porque en ese mundo surge la idea misma de Constitución y de una Constitución que desde el primer momento hay que explicar desde la teoría y la realidad del Derecho, surgiendo así la disciplina del Derecho Constitucional; y porque también en tal solar se ha desarrollado con especial fuerza la ciencia política. Puede parecer impertinente, aunque declaro solemnemente que la impertinencia no esté en mi ánimo, pero invito al profesor Lucas a que abra cualquier Constitutional Law americano y me diga qué tiene que ver eso con la filosofía política y con el análisis de la realidad social y política. ¿Es que también en Norteamérica -o en Alemania, o en Inglaterra, o en Suiza, o en Austria, o en Italia - ha surgido esa extraña epidemia de los administrativistas que han convertido el glorioso, por su amplitud ciclópea, Derecho Constitucional en un mínimo y reseco Derecho Administrativo? Por favor, no confundir: me estoy refiriendo a los libros de Constitutional Law, no a los de Government, confusión que nadie hace en Norteamérica (por cierto, que informo a mi contradictor que la ciencia política, o el Government, no se estudia, ni como disciplina complementaria, en las facultades o escuelas de Derecho de ese país).

Porque el honor que me hace mi querido crítico es verdaderamente notable: primero, parece creer que el Derecho Administrativo me lo he inventado yo; y segundo, también me atribuye como un logro propio nada menos que la pretensión de tratar los temas constitucionales como temas jurídicos. A esto último es a lo que Lucas llama «Derecho Constitucional como Derecho Administrativo», proposición temática que lleva al título mismo de su trabajo. No, 
mi amable antagonista: no me haga usted tanto honor, aunque se lo agradezca; mi osadía no llega a tanto, no ya mis logros; lo correcto es llamar a eso «el Derecho Constitucional como Derecho», simplemente, y eso es algo en lo que soy un modesto soldado de un ejército universal y bien nutrido. Mis trabajos de Derecho Constitucional serán buenos o malos, normalmente malos, lo reconozco sin falsa modestia; pero esa es la crítica - probablemente fácil- que hay que hacer de ellos y no la desvalorización previa y general de que no valen porque son Derecho Administrativo. Permítame que al menos en lo que sea o no sea Derecho Administrativo pueda opinar con alguna seguridad.

Y entremos en la famosa derivación del Derecho Constitucional comparado. Que lo que hacen la mayor parte de nuestros politicistas (como también los franceses) es «comparative politics» y no Derecho Constitucional es algo completamente obvio y no una ocurrencia más o menos irónica del llorado profesor Ramiro Rico, como parece creer Lucas Verdú. De nuevo he de proponer a éste la prueba más simple: abra un Comparative Constitutional Law americano (por ejemplo, el de M. Capelletti y W. Cohen, The Bobbs-Merril Company, Inc. Publishers, Indianápolis, 1979; o el de W. F. Murphy y J. Tanenhaus, St. Martin's Press, Nueva York, 1977) y dígame, por favor, qué tiene que ver eso con lo que aquí suele exponerse, con alguna excepción. Por otra parte, sigue la prueba, abra cualquiera de los innumerables libros sobre «comparative politics» (por ejemplo: Binder y Easton, Theory and Metbod in Comparative Politics, Prentice-Hall, 1965; G. A. Almond y C. B. Powell, Comparative Politics. A developmental Approach, Boston, 1966; H. A. Scarrow, Comparative Political Analysis. An Introduction, Nueva York, 1969; R. L. Merritt, Systematic Approaches to Comparative Politics, Chicago, 1970; G. Docker (Hrsg.), Vergleichende Analyse politischer Systeme, Freiburg ü. B., 1971; J. A. Bill y R. L. Hardgrave, Comparative Politics: The quest for Theory, Columbus, Ohío, 1973; B. N. McLeenan, Comparative Politics and Public Policy, North Scituate, Mass., 1980). Esto no es una fácil exhibición de bibliografía; es, simplemente, facilitar las cosas eludiendo una amplia discusión por la remisión a ciencias perfectamente constituidas, identificadas y nada equívocas. Que me diga el profesor Lucas Verdú de qué lado se inclina lo que él, en solitario, persiste en llamar Derecho Comparado. El profesor Ramiro Rico era un estudioso de un rigor absoluto, rigor y conocimientos disimulados en un pudor irónico y escéptico, pero no solía decir precisamente palabra de más.

Le citaré aún dos ejemplares monografías de Derecho Constitucional Comparado, una de un agudo profesor italiano con quien el artículo que comento confiesa alguna relación, y va en su honor, el de Antonio La Pergola, Residui «contrattualistici» é struttura federale nell'ordinamento degli Stati Uniti, Milano, 1969; otro, francés, más reciente, que cito porque se alinea en la creciente corriente antiduvergeriana, el de C. Greywe-Leymarie, Le Féderalisme coopératif en Republique Fédérale d'Allemagne, París, 1961 (el prologuista M. Frommont, un ejemplar jurista comparatista; subraya en el prólogo, página $\mathrm{V}$, que el libro «es un verdadero libro de Derecho. No es una simple descripción de instituciones tal como existen y funcionan; es un análisis de problemas jurídicos que plantea el paso de un federalismo fundado sobre la 
autonomía de los Estados miembros a un federalismo fundado sobre la cooperación del Estado federal y de los Estados miembros... los juristas franceses tienen mucho que aprender de los juristas alemanes, siempre preocupados de no dejar las cosas en el claroscuro de los compromisos políticos»).

Todo esto me resulta un poco sorprendente: que tenga que ser yo quien diga al profesor Lucas Verdú que lo que él está haciendo, y meritoriamente, por cierto, no es Derecho Constitucional, como él parece creer de buena fe. Que, a su vez, él pretenda que lo que yo llamo Derecho Constitucional no es sino Derecho Administrativo, es también sorprendente. Hay aquí un gigantesco malentendido. ¿Cómo explicarlo? El ha dado su versión. Permítaseme, en mi turno, la mía.

Aquí hay que remontarse un poco a los fundamentos mismos de la teoría juridica. Lo haremos brevísimamente y por referencia a valores identificados y conocidos. Uno es el schmittianismo (si me permite Lucas una vez más esta libertad formulativa, que también me reprocha en su implacable crítica). El artículo protesta con ira de una, quizá excesiva, generalización que yo hacía en el prólogo impugnado sobre la influencia que la crítica de Carl Schmitt al constitucionalismo liberal había ejercido en nuestra doctrina. Pero resulta que nada más fácil que demostrar que Lucas Verdú mismo es precisamente uno de los autores que refleja aún dicha influencia. Citemos de su artículo «Socialismo y Derecho Constitucional», publicado en el número monográfico «Socialismo y Constitución» de la revista Sistema, números 17-18, abril de 1977. En la página 38 cita a Schmitt como un autor que introduce su obra «en momentos de la clamorosa crisis del Estado liberal burgués de Derecho». ¿Qué crisis? - pregunto yo-; más bien habría que decir en el momento del clamoroso y torticero ataque contra el Estado de Derecho democrático y liberal, ataque que triunfó en unos cuantos países ( $y$ así les ha ido a todos ellos), pero no precisamente en todas partes; desde los reductos que entonces quedaron intactos pudo reconstruirse el mecanismo entero de ese Estado de Derecho, con ciertos correctivos en los países europeos, en la segunda posguerra y finalmente, como ejemplo feliz y más reciente, en el nuestro.

En ese artículo, que se incluye en una colección de trabajos preparados para proporcionar ideas al proceso constituyente abierto a comienzos de 1977 con la aprobación de la Ley para la Reforma Política, se parte justamente de una especie de derribo general del sistema constitucional tradicional. El schmittianismo se dobla aquí de un cierto marxismo elemental, al que luego aludiremos, que le lleva nada menos que a considerar modelos posibles en el constitucionalismo portugués y en el del Este. Felizmente, nuestros constituyentes no siguieron esas extrañas sugerencias.

Pero, al margen de este trasfondo general, en el que parecen unirse Schmitt y Marx, agua y aceite, por cierto, en el propio artículo que me dedica el profesor Lucas Verdú denota lo arraigado de algunas ideas-fuerza del primero. Así la sorprendente afirmación de que en la Constitución «se encuentran desparramados diversos artículos de índole administrativa, fiscal, procesal, penal y de Derecho privado que no son materialmente constitucionales, aunque lo sean formalmente» (pág. 17), afirmación que no se entendería por ningún constitucionalista actual en cualquier país occidental, y que es 
rigurosamente tributaria de la distinción de Schmitt entre Constitución y Leyes constitucionales; quizá por ello nos reconoce generosamente a los administrativistas la posibilidad de hablar «con singular preparación» nada menos que sobre estos aspectos de la Constitución: descentralización, reparto de competencias, materias procesales y, en general, aquellos asuntos «en los que domina el aspecto organizativo y procedimental» (pág. 20); no está nada mal, después de todo, especialmente si en esa materia procesal incluye toda la actuación del Tribunal Constitucional y, correlativamente, la técnica jurídica de la libertad (aunque quede fuera toda su suculenta filosofía; no creo que nos discuta demasiado tampoco la materia de fuentes del derecho, según las prácticas respectivas de unos y otros). Así, también, es claramente schmittiniana, y de manera muy especial, la idea que Lucas tiene de la justicia constitucional, cuestión a la que luego aludiremos.

Lucas Verdú me reprocha, cómo no -estaba ya advertido en el propio prólogo-, que mi concepción de la Constitución como una norma jurídica, a la que hay que tratar, interpretar y aplicar con técnicas jurídicas, es una típica expresión de positivismo y de formalismo jurídicos. Repite, pues, el alegato de Schmitt contra Kelsen, en la famosa polémica de los años treinta, caros al autor. Ahora bien, desde entonces han transcurrido más de cincuenta años, no en vano, y la alternativa entre decisionismo y normativismo positivista ya no es reconocible. Así, pasando ya a mi pequeño caso, podrán sin duda destacarse muchos pecados míos como jurista, pero me sorprende que se me pueda imputar seriamente el de positivista. Si alguna significación, modestísima, por supuesto, he podido tener en la historia de nuestro Derecho Administrativo, que es donde mi ciencia jurídica se ha ejercitado predominantemente, me parece que puede estar justamente en haber contribuido en algo a una superación de ese positivismo y ese formalismo jurídicos que asolaban nuestro Derecho público. El profesor Lucas Verdú no parece estar al tanto de los detalles de nuestro Derecho Administrativo, pero nada más fácil que preguntar, si fuese menester y si quiere ahorrarse una lectura prolija de textos y un conocimiento detallado de posturas, que me parece que son inequívocas. Por ello creo que puedo decir que nada me conviene menos como jurista que el mote de positivista; sobre la superación del texto de la Ley como criterio único de decisión jurídica, sobre los principios generales del Derecho y su papel relevante, sobre la justicia material y la libertad como fin último de la aplicación de la norma, podría remitir a muchas páginas propias, y también a páginas ajenas, incluso no limitadas a tratadistas de Derecho Administrativo, en que se me reconoce algún papel en la lucha por una concepción sustancial y no formalista del Derecho.

Bien. Pero lo que mi amable crítico quiere decir, en realidad, no es que yo sea positivista, al menos en el sentido técnico de este concepto, sino que respeto la positividad del Derecho. Es un reproche que acepto con orgullo, el orgullo justamente de seguir siendo un jurista, porque sin positividad no hay Derecho, aunque pueda haber moral, o militantismo político, o filosofía, muchas cosas, sin duda, pero otras. En una frase de Forsthoff, discípulo de Schmitt, por cierto, que escribe ya desde la nueva situación democrática, «die Ueberwindung des Positivismus is nicht die Preisgabe der Positivität des Rechts überhaupt», esto es, «la superación del positivismo no implica en 
modo alguno el abandono de la positividad del derecho». El profesor Lucas cree que la superación del positivismo ha de llevar a la destrucción del Derecho o, al menos, a la de su objetividad, a la de la técnica jurídica que para su interpretación y aplicación ha depurado la humanidad en un proceso secular. Ahí es donde no le sigo y donde creo que difícilmente le puede seguir ningún jurista verdadero, $y$, por supuesto, ningún constitucionalista en ejercicio en los países con justicia constitucional establecida. Es aquí, justamente, donde está nuestro punto de discrepancia.

$\mathrm{El}$ artículo que comento, como otros muchos trabajos del profesor Lucas, están llenos de desdén por la técnica jurídica, que se intenta desvalorizar en bloque a través del simple epíteto de formalistas, lanzado como un proyectil, sin mayor análisis. Eso es inadmisible, mi querido amigo. Eso, lejos de justificarse en una finalidad progresista, lleva derechamente a la guerra de poderes, de todos contra todos, $y$, por ende, al final, con seguridad, al predominio de los más fuertes, de los prepotentes, al aplastamiento seguro de los débiles. El Derecho y su objetividad son, entre otras cosas, un escudo de la libertad, la protección del débil, el límite infranqueable al poderoso. Ignorarlo es ignorarlo todo del Derecho y del Derecho público, en particular, lo que es sorprendente en quien reclama para sí y sus tendencias un monopolio en bloque de una rama jurídica, y nada menos que de la Constitucional, sustento y base de todo el ordenamiento.

Aquí viene a cuento el tema del marxismo. Resultaría impertinente un debate general sobre el marxismo y su valor actual, un tema de alto porte. Bastará con referirse a lo que en realidad es un tema distinto, al marxismo vulgar o elemental, que es aquel en que incurren quienes (con conciencia clara o sin ella) pretenden expeditivamente destruir desde la crítica marxista del orden, que revela una infraestructura de intereses generando y sosteniendo dicho orden, toda la objetividad y positividad del Derecho. Lucas Verdú (ver, por ejemplo, el citado artículo de Sistema) pretende justificarse en esas condenaciones de marxismo vulgar (el Derecho constitucional como instrumento de la burguesía, o del capitalismo, o de los monopolios, o de las multinacionales, o cosas de análogo tonelaje y matiz) para arrasar toda la técnica jurídico-constitucional. Permítame decirle, con todo afecto, que su posición recuerda también en esto la de los años treinta y la de Schmitt en particular. ¿Dónde se encuentra hoy eso? Esos juicios globales descalificatorios llevarían derechamente a la revolución, y hoy ya en el mundo europeo parece superada esa fase; el eurocomunismo no es más que la adaptación a esa nueva realidad. Si no hay revolución ha de haber Derecho, y si ha de haber Derecho éste no puede subsistir sin técnica jurídica; sin lo que, no sé por qué, Lucas se empeña en llamar Derecho Administrativo. Excluye la técnica jurídica, a mi juicio, el llamado uso alternativo del Derecho, si quiere más concreción, y así he tratado de justificarlo más de una vez. La guerra en la interpretación del Derecho según las concepciones políticas de los jueces, que a eso lleva «el uso alternativo», es una guerra más, y especialmente desgarradora y aguda, una guerra desarrollada en golpes de mano sucesivos, plurales y contradictorios, que usurpan el poder legislativo $-\mathrm{O}$ el constituyente, en el caso de la interpretación constitucional- del pueblo, una guerra de las que la objetividad del Derecho (y en el caso concreto de la Constitución, su 
«valor superior» del pluralismo político, art. 1.1) intenta justamente excluir en el seno de la sociedad como el primero de sus fines.

Recojo así derechamente la destacada imputación que Lucas Verdú me hace de ser un antimarxista visceral. Este concepto suele utilizarse en la lucha política para llamarle a uno reaccionario; no creo que sea esa la intención de mi colega, pero si lo fuera, creo - y conmigo quizá todos mis discípulos, que jamás me han visto así- que se equivoca. Las dos frases en que apoya ese juicio no pueden ser más inoportunas. Lo que reprocho a Duverger acabo de decirlo: que en nombre de un realismo del cuadro de intereses que subyace a las instituciones descalifique sin más la técnica jurídica y justifique así su abandono y su paso a los métodos de análisis social; hay textos explícitos suyos en ese sentido, que Lucas conoce perfectamente y que por ello excuso.

En ese reproche acabo de ratificarme de manera explícita, y creo que no visceralmente, racionalmente, que es como suelo intentar operar, aunque con mejor o peor fortuna, naturalmente.

La frase de mi prólogo al libro de Antonio Esteban, que también cita Lucas como muestra de mi antimarxismo, me parece especialmente mal escogida. Por una parte, porque refleja un hecho del que me limito a dar cuenta, que Esteban, como nos consta a todos sus amigos, a quienes difícilmente podrá desautorizar en bloque Lucas por una simple sospecha de parcialidad, abandonó en un momento el marxismo militante porque en él no cabía su generosidad y su espíritu; una experiencia, por cierto, repetida con alguna frecuencia. Por otra parte, porque cito allí un libro de Ernst Bloch, que es quien critica la interpretación institucional de un cierto marxismo de manual (y de realidad práctica: la condena de los derechos fundamentales como técnicas burguesas y antisociales); ahora bien, espero que Lucas no se atreva a imputar precisamente a Bloch - la cima del pensamiento marxista, probablemente lo que de él queda en este momento de más vivo- ese famoso antimarxismo.

La técnica jurídica, que incluye predominantemente valores materiales y no sólo lógica formal sobre textos legales, es especialmente imprescindible en la justicia constitucional, y me atrevo a decir que de manera singular en el caso español. Aquí sí que hay un completo contraste entre las posiciones del profesor Lucas y las mías. Remito no sólo al artículo que comento, donde esa discrepancia se instrumenta como una crítica a mis opiniones, sino también a su trabajo «Política y justicia constitucionales. Consideraciones sobre la naturaleza y funciones del Tribunal Constitucional», recogido en el tomo II de la obra colectiva El Tribunal Constitucional (Dirección General de lo Contencioso del Estado, Madrid, 1981, págs. 1483 y sigs.), artículo, por cierto, que es un avance de su preocupación por lo que ya ahí llama «administrativización» del Derecho Constitucional. El profesor Lucas cree firmemente, al parecer, que si se deja a los Tribunales Constitucionales operar con simples métodos jurídicos, la Constitución concluirá por ahogar la evolución política y el progreso social, y por ello se esfuerza en apelar a nuestro propio Tribunal a que tome conciencia de su papel político y opere como tal, rompiendo, pues, según parece, las técnicas jurídicas formadas por la burguesía en defensa de sus conocidos intereses; por aquí es donde, en definitiva, ve él el mayor riesgo de lo que llama la administrativización del Derecho Constitucional. 
Sería totalmente impertinente que yo tuviese que hacer aquí una teoría de la justicia constitucional; me bastará con remitirme a lo que sobre el tema he dicho en el segundo trabajo del libro que ha suscitado la crítica de mi querido colega, aun pasando por el juicio negativo que a éste merece dicho trabajo, desde el título mismo, juicio que, naturalmente, respeto. Me parece que, sobre esa exposición anterior, bastará que puntualice dos cosas: todos los Tribunales Constitucionales del mundo actúan como efectivos órganos jurisdiccionales, con la técnica jurídica de aplicar una norma preexistente y objetiva a casos singulares, y en eso se distinguen precisamente de los órganos puramente políticos de composición de conflictos (véase, por ejemplo, la última exposición de A. Pizorusso, en el tomo Garanzie costituzionali del gran Commentario della Costituzione de Branca (Bologna-Roma, 1981, págs. 11 y sigs.; por cierto, que en el exergo de este espléndido volumen - en colaboración con Volpe, Sorrentino y Moretti- podrá verse un intento expreso por depurar la mejor «scuola costituzionalistica italiana» -reconociendo a la vez los «importanti contributi di processualisti e amministrativisti»-, en el sentido de una juridificación definitiva de la misma, frente a otras veleidades: página IV); la experiencia universal y más que secular de ese contraste es abrumadoramente favorable a la fórmula de Tribunales constitucionales jurisdiccionales, digamos incidentalmente (piense sólo en la reciente experiencia portuguesa, tan cara a Lucas, del Consejo de la Revolución). Y, segundo, la conversión de la Constitución en norma judicial de decisión plantea problemas jurídicos de interpretación nada vulgares, pero que se han demostrado perfectamente resolubles en el seno de la técnica jurídica más depurada, problemas donde la fórmula misma de los Tribunales Constitucionales se juega su existencia, hoy ya, sin disputa, no cuestionada allí donde tales Tribunales funcionan. Esta técnica jurídica incluye, por supuesto (como es común en la aplicación de cualquier rama del Derecho para los juristas no positivistas), una Wertungsjurisprudenz y una inexcusable atención «a la realidad social del tiempo en que (la norma) ha de ser aplicada», como establece hoy con simplicidad y normalidad el artículo 3.1 del Código Civil para todos los jueces. Pretender identificar, como hace explícitamente el profesor Lucas Verdú, la técnica jurídica con una técnica positivista y de jurisprudencia de conceptos, que lleva por sí sola al conservadurismo, al freno y a la limitación del cambio, es una muestra más de que dicho profesor, autorizado politólogo, tiene una idea un poco insuficiente de por dónde andan hoy la teoría y la práctica del Derecho.

¿Qué le permite suponer, en efecto, como nos recuerda en las páginas 15 y siguientes de su crítica, que los valores presentes en la Constitución no son funcionalizables jurídicamente? Justamente los Tribunales Constitucionales han demostrado una acusada sensibilidad para esas «ventanas» que airean el ordenamiento y evitan su rigidez, para hacer de la Constitución una'living Constitution, una norma que vive con su pueblo y que se adapta a los tiempos con flexibilidad y suavidad, excusando así las crisis constitucionales periódicas, que son la única alternativa real a la justicia constitucional. Permíteme, querido director, que transcriba una frase del juez Holmes - un jurista donde los haya - que gustan de repetir los constitucionalistas americanos: «the provisions of the Constitution are not mathematical formulas having their esence in their form; they are organic living institutions». $\mathrm{Y}$ esto no son 
meras expresiones literarias; son definiciones del papel cumplido por el Tribunal Supremo de los Estados Unidos, y hoy por los Tribunales Constitucionales alli donde existen y funcionan con corrección. Esa capacidad de adaptación del texto constitucional a las circunstancias cambiantes es uno de sus merecimientos insustituibles. El riesgo que ve Lucas, como antes Schmitt, de una petrificación del texto y de un bloqueo del cambio es, precisamente, el riesgo que ellos sortean como ninguna otra fórmula institucional, lo cual es, por de pronto, un hecho establecido y no ya una simple opinión. Por eso resulta inexplicable que Lucas pretenda apoyarse en Smend para justificar ese juicio, cuando el propio Smend, espléndido jurista, ha sido perfectamente explícito en sentido contrario (como mi criticado trabajo expone con cierto detalle).

En el Derecho mismo, por tanto, un Derecho afinado y perfeccionado en sus técnicas, pero sin hacer perder a éstas su objetividad y generalidad, están, pues, los remedios mejores, los únicos disponibles, respecto a los riesgos que en el encerramiento de los Tribunales Constitucionales en la técnica jurisdiccional veían Carl Schmitt en su tiempo y Lucas Verdú, extemporáneamente, cincuenta años después, cuando la experiencia de estos Tribunales es ya concluyente. Así justifica ese aserto, además de esa experiencia general, el excelente trabajo de Otto Bachof que me permití por ello resumir con cierta amplitud en mi trabajo sobre el Tribunal Constitucional (como antes el mismo autor había enfatizado en su discurso rectoral: cito por la traducción española, que yo mismo estimulé, por cierto, un poco antes de que pudiesen sospecharse intereses profesionales - ver mi amplia reseña en el número 105 de la Revista de Estudios Políticos, 1959-, Jueces y Constitución, 1961).

Donde sería absurdo buscar la salida a esos riesgos es en una incitación a los jueces constitucionales a olvidar su papel de jueces y a convertirse en agentes políticos, haciendo valoraciones directamente traducibles desde el análisis o la ciencia política a la decisión del Tribunal, que es lo que propugna mi contradictor con toda convicción. Los juristas, en una excelente frase de Arthur Kaufman que he citado más de una vez, tienen «profundamente arraigado un horror iuris naturalis» que les manipule «desde arriba» las decisiones jurídicas; más aún si ese «arriba» no es ni siquiera un supuesto Derecho Natural ahistórico, sino las corrientes políticas mismas que pugnan en el vórtice de la historia, como se nos propone. Eso, primero, es destruir con seguridad a los Tribunales Constitucionales en un plazo corto, pues ¿dónde está la legitimidad de estos Tribunales para imponer sus propias concepciones políticas? ¿Por qué las fuerzas políticas reales van a tolerar tamaña intromisión? ¿Desde qué autoridad podrían hablar esos extraños jueces que usurpan al pueblo sus poderes? Parece evidente que todo intento de desvincular a los jueces del Derecho, esto es, de la soberanía popular, inclinándoles al decisionismo, es radicalmente antidemocrático, por debajo de las apariencias.

Pero no sólo eso, y más grave aún: esa supuesta alternativa lleva derechamente a la destrucción de la Constitución misma. Los Tribunales Constitucionales sólo como comisionados de ésta pueden hablar, imputándola sus propias decisiones, proceso de imputación que, justamente, sólo a través de la interpretación jurídica de la Constitución, de la hermenéutica como operación típicamente jurídica para pasar de la norma a la aplicación, puede 
lograrse. Si el Tribunal prescinde de esa operación hermenéutica y se lanza a decidir por sí mismo desde valoraciones políticas propias habría roto la norma cuya defensa tiene encomendada.

Rotura gravísima e irreparable. Pensemos un momento en el caso español en que se ha logrado, tras más de un siglo de luchas civiles, el milagro histórico de una Constitución aceptada por todos. Sólo el Tribunal Constitucional podrá mantener vivo y actualizado ese consenso básico, fundamento esencial de nuestra convivencia, y ello guardando fidelidad absoluta a ese texto sagrado (sagrado por su origen, por imperfecciones que contenga, las cuales, en todo caso, los juristas precisamente disponen de técnicas para paliar), no intentando desconocerlo o alterarlo en nombre de un progresismo romo y elemental, que generaría inmediatamente la reacción contraria y que al final nos abocaría inevitablemente a un nuevo enfrentamiento y a una desgarradura incalculable.

Sé muy bien, por supuesto, que nada de eso desea mi querido colega; pero me permito incitarle a que medite si sus escepticismos sobre la juridificación del Derecho Constitucional y sobre el trabajo del Tribunal Constitucional, y su apelación a la introducción directa por éste de valoraciones nudamente políticas y, además, de un socialismo utópico (véase más adelante sobre esto), no conducirían inevitablemente a ese resultado.

Henos aquí, pues, conducidos a un final de alguna trascendencia, que quizá no convenga perder de vista entre las triviales cuestiones de las rivalidades de cuerpos y de especialidades. En Derecho no hay errores impunes; todos llevan a la injusticia o al desorden, precisamente porque el Derecho es un sistema de paz, de libertad y de justicia.

¿Me permites, querido Director, que invoque de algún modo mi propia experiencia de juez de materia constitucional? Pues sobre esa materia opera el Tribunal Europeo de Derechos Humanos, un Tribunal de 21 jueces que enjuicia no sólo hechos, sino el Derecho de 18 países europeos, un Tribunal que es por ello Tribunal de Leyes, incluso para los escasos países europeos, como Inglaterra, que carecen de justicia constitucional (he aquí corroborado mi juicio sobre el final próximo de la sumisión de la Constitución inglesa al Parlamento ordinario; ¿sabe Lucas que, además del Convenio europeo, que hoy ya se sobrepone al viejo dogma de la soberanía del Parlamento, una reciente corriente de opinión propugna la resuelta formulación de un Bill of Rights superlegal y, por tanto, con judicial review?; contesto así a otra crítica marginal de mi censor; me permito remitirle, entre una amplísima bibliografía, a J. Jaconeli, Enacting a Bill of Rights. The legal problems, Clarendon Press, Oxford, 1980; la posición del Partido Laborista sobre el tema, en el opúsculo «United Kingdom Charter of Human Rights: a discussion document for the Labour Movement», 1976; un documento oficial que prueba que no se trata de simples sugerencias: House of Lords, «Report of the Select Committee on a Bill of Rights», 1978). Pues bien, la totalidad de esos jueces, que han de imponer un standard común mínimo de libertad en toda Europa, son juristas puros, o procedentes de los Tribunales Supremos nacionales, o de las Facultades de Derecho, o de los Colegios de Abogados; ni un solo politólogo; pero, sobre todo, sus métodos son de pura hermenéutica jurídica, y sería extraño que pretendieran ser otra cosa, erigiéndose en cámara legisla- 
tiva de un continente tan diversificado y problemático, y que trataran de imponer a la soberanía de 18 Estados obligaciones que éstos no aceptaron al vincularse al Convenio Europeo para la protección de los derechos humanos y libertades fundamentales. Esta regla básica de Derecho Internacional es aquí un argumento adicional de primer orden para acantonar al Tribunal en una labor puramente hermenéutica de dicho Convenio Europeo. Y bien: ahí está la labor de ese Tribunal y con ella una muestra excepcional de la fertilidad de los métodos del Derecho. Añadiré que en los cuatro años que yo llevo en él se han producido casi la mitad de todas las sentencias que ha dictado en veintisiete años de funcionamiento. Acaso no sea una experiencia del todo trivial.

$\mathrm{Y}$ ahora muy pocas palabras ya sobre la «reducción» marxista que intenta de mi supuesta ideología, aunque Lucas tome como tal la de mi simple condición de jurista, en lo que estoy acompañado por los juristas de las ideologías políticas y personales más diversas. Es un tema de escasísimo interés objetivo, es más que evidente. El juego de ese reduccionismo (yo podía hacer lo mismo de mi contradictor; por ejemplo, quizá no me sería difícil un reduccionismo psicológico de su reacción; pero entiendo, contra lo que parece ser la opinión de mi antagonista, que las polémicas científicas deben huir resueltamente de lo personal) suele tener interés cuando se manejan datos específicos y se interpretan con perspicacia y penetración. Permítame mi querido colega que le diga que me parece que no es el caso de su análisis.

Dice de mí que soy el jurista oficial de la democracia española. De ser «oficial» no me hubiese sorprendido tanto un juicio tan fuera de toda medida; pero, en fin, debo decir que, en el fondo, no me disgusta que haya podido ver en mí un defensor convencido, hasta identificarme con ellos, de los valores y de la esperanza suscitada por nuestra Constitución, en cuya elaboración y aprobación cualquiera sabe que carecí de la más mínima intervención, fuera de mi voto de ciudadano; es, pues, un honor, injustificado, pero que acaso he de agradecer.

A cuenta de mi «oficialismo» incluye Lucas también mi participación en la Comisión de expertos que preparó los pactos autonómicos de julio de 1981 entre UCD y el PSOE, pactos que han dirigido desde esa fecha toda la política autonómica - comenzando por la formulación y aprobación de los Estatutos entonces pendientes-. Lucas, por cierto, ve reflejados en dicho informe todas las limitaciones del administrativismo, aunque sin especificarlas luego. Me he propuesto, desde que quedó concluido, no hablar del trabajo de esa Comisión (Comisiones análogas, por cierto, las ha habido en todos los países sobre el mismo tema: Tröger en Alemania, 1966 - reforma del sistema federal y adopción del esquema de federalismo cooperativo-; Killbrandon en Inglaterra, 1973, sobre el gran proyecto de «devolution of powers» regional; Aubert-Macheret en Suiza -creación del nuevo Cantón del Juraen 1975; Gianninni en Italia - sobre «completamento» del ordenamiento regional-, 1976; Lalumière en Francia, 1981, para la preparación de la Ley Deferre de descentralización, que acaba de ser aprobada; y los periódicos informes americanos de la «Advisory Commission on Intergovernmental Relations» a partir de 1958; ¿acaso serán «juristas oficiales» todos sus respectivos presidentes?), trabajo entregado por su propia significación a la polémica po- 
lítica, pero me bastará con decir dos cosas que, al menos, supongo que me concederán los impugnadores: que ese trabajo no fue solicitado, y más bien aceptado como una grave carga, con algún sentido de la responsabilidad; y segundo, que lamentaría que en el juicio de Lucas y de algunos otros pudiera estar presente ese minúsculo problema sobre rivalidades profesionales al que el artículo que comento se debe, porque me parece que en el tema hay comprometidos valores de alguna mayor significación; sólo conozco un verdadero análisis general del trabajo cumplido por esa Comisión: el realizado por un constitucionalista italiano, Luciano Vandelli, y me parece algo mejor construido que esos frívolos juicios globales descalificatorios, que, por supuesto, pueden tener plena razón, pero que son frívolos por su falta de fundamentación y por la latencia de esos lamentables problemas profesionales.

Me reprocha luego Lucas, en la operación de «reducción» ideológica, mi antimarxismo visceral, a lo que ya he replicado. Finalmente, me dice defensor dei neocapitalismo y del «american way of life».

Lo del neocapitalismo tiene en Lucas Verdú un significado muy preciso: es el estadio anterior a la sociedad sin clases autogestionada, que él propugna con admirable entusiasmo en su citado artículo «Socialismo y Derecho Constitucional»; en la pág. 39 de este trabajo descubro que «las bases socioeconómicas del Estado y de su Constitución responden todavía — salvo el caso de formalización del Estado en la URSS y en las democracias populares, controladas por sus correspondientes Partidos Comunistas- al neocapitalismo». En su otro artículo sobre «Política y Justicia Constitucionales», también citado, precisa más: «Nuestro Tribunal Constitucional corresponde al Estado social de Derecho, que descansa en una estructura socioeconómica neocapitalista» (pág. 1520). Es, pues, exacto, debo reconocerlo, que ése es mi mundo; ni el modelo de las democracias populares ni la utopía libertaria de la sociedad autogestionada y sin poder me estimulan científicamente demasiado, debo confesarlo.

¿Y mi papel de propugnador del «american way of life»? Eso sí que me deja perplejo. ¿Dónde he defendido yo, o de qué actitud mía puede inferirse tal preferencia, la coca-cola, o los hamburger, o los tragaperras, o el baseball, o cosas análogas? Temo que se trate acaso de un simple error de imprenta: ¿no querrá decir «american way of law» y deducir esa supuesta preferencia de mi utilización de fuentes del Derecho Constitucional americano? Pero aun hecha esa corrección, me seguiría sorprendiendo que un pretendido constitucionalista me reproche el conocimiento y la utilización de nada menos que del Derecho Constitucional americano, el primero de todos en la historia y uno de los más notables y más instructivos en su desarrollo. ¿Operará aquí el «antiamericanismo visceral» que suele presentarse en ciertos pretendidos progresismos? Sería asombroso que ese reflejo elemental se prolongase a la ciencia misma, aunque quizá la versión vulgar de la doctrina de la superestructura pueda también llegar a explicarlo.

Terminaré esta carta (cuya longitud, con la que no contaba, acaso excuses, quetido director, en el hecho de haber reducido al mínimo las cuestiones personales y de haber desarrollado más las que pueden presentar un cierto interés objetivo), terminaré esta carta con un simple dato. El profesor Lucas Verdú ha reeditado no hace mucho el tomo I de su notable Curso de Dere- 
cho Político. En la contraportada puede leerse: «Segunda edición, 1976» y «Reimpresión, 1980». Es decir, que para el contenido del libro no parece tener el menor interés la aparición de la Constitución de 1978, pequeño detalle del que puede prescindirse. En el tomo II de esta misma obra, que se presenta ya como «3. ${ }^{a}$ edición revisada», y aparece en 1981, son muchos los capítulos, como el XIII de la parte $3 .^{\mathrm{a}}$ titulado «Problemática actual de la justicia constitucional y del examen de constitucionalidad de las leyes», en que ni siquiera se cita la Constitución española de 1978; en otros capítulos de la misma parte $3 .^{\mathrm{a}}$, como el dedicado a «garantías constitucionales», se citan las Constituciones de Renania-Palatinado, Checoeslovaquia, Baviera, Bélgica, la de Weimar, etc.; pero a la española de 1978 se dedican sólo 19 líneas entre 22 páginas, líneas que son una simple transcripción del art. 55; en el capítulo IV de la misma parte («Constitución, Administración, Planificación, tres principios básicos reguladores de la convivencia política occidental»), 28 páginas, tampoco se cita una sola vez a la pobre Constitución española, que, no obstante, incluye preceptos expresos sobre esa temática. Tampoco se cita a ésta una sola vez en el capítulo VIII de la misma parte ( Poder constituyente y rigidez constitucional»), 13 páginas; en el IX, que continúa el anterior, sobre la naturaleza y consecuencias de la rigidez constitucional, tampoco nuestra pobre norma suprema merece una sola alusión, etc. ¿A qué seguir? Me parece difícil poder aportar una prueba más categórica de que lo que el autor llama Derecho Político en esa obra, sea lo que sea, no tiene nada que ver con el contenido de Derecho Constitucional o de la Constitución.

Trabajemos todos, desde nuestras respectivas especialidades e inclinaciones, en conseguir que nuestra Constitución llegue a ser la norma efectiva que presida la convivencia de los españoles, sin exclusiones ni monopolios. Vayamos a las cosas y no a las personas, al Derecho Constitucional real y no a los supuestos títulos personales que puedan dar o negar «derecho» a hablar de él. Sean bienvenidos todos los esfuerzos y proscribamos de una vez las proscripciones de unos sobre otros. Il est interdit d'interdire!

Un saludo cordial, con mis disculpas.

Eduardo García de EnTERría 